https://doi.org/10.47370/2078-1024-2021-13-3-48-56

УДК 947.081:[297:342.5](470.62)

Кандор Р.С.

ПОЛИТИКА ОРГАНОВ ВЛАСТИ КУБАНСКОЙ

ОБЛАСТИ В ЭТНОКОНФЕССИОНАЛЬНОЙ СФЕРЕ: ОПЫТ РЕГУЛИРОВАНИЯ ДЕЯТЕЛЬНОСТИ МУСУЛЬМАНСКОГО ДУХОВЕНСТВА (1880-Е ГГ.)

\author{
Кандор Руслан Султанович, \\ кандидат исторических наук, ведущий научный сотрудник отдела исто- \\ 'рии ГБУ РА «Адыгейскийреспубликанский институт гуманитарных иссле- \\ дований им. T.Мь Керашева», Майкоп, Россия, \\ e-mail: kandor.ruslan@mail.ru, \\ тел.: +7 (906) 4385989
}

Аннотация

В настоящей статье рассматривается исторический опыт регулирования органами власти Кубанской области в 1880 -е гг. вопросов духовного управления мусульманскими сообществами, назначения аульных мулл, повышения роли кадиев горских словесных судов. Вопрос духовного управления мусульманскими сообществами имеет важное значение для понимания процесса становления российского гражданского управления на Северном Кавказе, которое было связано с преодолением как предвзятого отношения чиновников к кавказским народам, так и страхов, например адыгов (черкесов) потерять свою этническую идентичность и связь с мусульманским миром. Проявлялось такое негативное состояние черкесского населения Кубанской области в перманентном стремлении их переселиться на постоянное жительство в Турцию.

И в контексте рассмотрения российско-кавказских отношений становится актуальным исследование такого положительного опыта регулирования вопросов духовного управления мусульманскими сообществами Северного Кавказа.

В статье автор в ходе раскрытия проблемы следовал принципу научности и принципу объективности в проведении исследования, им был использован соответствующий широкий круг источников по истории адыгов (черкесов), включавший и большой объем архивного материала, предполагающий всесторонний охват исторических фактов по данной проблеме. Следование автора принципу историзма, позволило рассмотреть деятельность органов гражданской власти Кубанской области в динамике от фактических событий в конкретных исторических условиях до рассуждений об их причинах и последствиях.

Автор приходит к выводу, что российские власти поставили вопрос об улучшении организации деятельности мусульманского духовенства, стараясь при этом не создавать перегруженный бюрократический аппарат. Мусульманское духовенство в уездах Кубанской области, нуждавшееся в контрольной духовной власти, получило ее в лице кадиев уездных Горских словесных судов.

Ключевые слова: Кубанская область, духовное управление, регулирование, начальник области, начальник уезда, горский словесный суд, кадий, эфенди, аульный мулла

$$
-48-
$$


Для цитирования: Кандор Р.С. Политика органов власти Кубанской области в этноконфессиональной сфере: опыт регулирования деятельности мусульманского духовенства (1880-е г2.) // Вестник Майкопского государственного технологического 'университета. 2021. Том 13, № 3. C. 48-56. https://doi.org/10.47370/2078-1024-2021-13-3-48-56.

\title{
Kandor R.S. \\ POLICY OF THE KUBAN REGION AUTHORITIES INTHE ETHNO-CONFESSIONAL SPHERE: EXPERIENCE OF REGULATING THE ACTIVITIES OF THE MUSLIM CLERIC (1880S)
}

\author{
Kandor Ruslan Sultanovich, \\ Candidate of History, a leading researcher of the Department of History of FBI \\ $R A$ "The Adygh Republican Institute of Humanitarian research namediafter TM. \\ Kerashev", Maykop, Russia, \\ e-mail: kandor.ruslan@mail.ru, \\ tel.: +7 (906) 4385989
}

\section{Annotation}

The article examines the historical experience of regulation of the issues of spiritual authorities of Muslim communities in 1880 s by the authorities of the Kuban region, as well as appointment of aul mullahs, increasing the role of qadis in mountain verbal courts. The issue of spiritual governance of Muslim communities is important for understanding the process of Russian civil governance formation in the North Caucasus, which was associated with overcoming both the biased attitude of officials towards the Caucasian peoples and fears, for example, of the Adyghs (Circassians) of losing their ethnic identity and connection with the Muslim the world. Such a negative state of the Circassian population of the Kuban region manifested itself in their permanent desire to move to Turkey for permanent residence.

And in the context of examining the Russian-Caucasian relations, it is relevant to study such a positive experience in regulating the issues of spiritual governance of the Muslim communities of the North Caucasus.

In the article the author followed scientific principles in conducting the research and used a wide range of references on the history of the Adyghs (Circassians), which also included a large amount of archival material, suggesting a comprehensive coverage of historical facts on the issue. The author's adherence to the principle of historicism made it possible to examine the activities of the civil authorities of the Kuban region in dynamics from actual events in specific historical conditions to reasoning about their causes and consequences.

The author concludes that the Russian authorities raised the issue of improving the organization of the activities of the Muslim clergy, while trying not to create an overloaded bureaucratic apparatus. The Muslim clergy in the districts of the Kuban region that needed control spiritual power, obtained it in the person of qadi of the district Gorsky verbal courts.

Keywords: the Kuban region, spiritual administration, regulation, head of the region, head of the district, mountain verbal court, qadi, efendy, aul mullah

For citation: Kandor R.S. Policy of the Kuban region authorities in the ethno-confessional sphere: experience of regulating the activities of the Muslim cleric (1880s) // Vestnik Majkopskogo gosudarstvennogo tehnologičeskogo universiteta. 2021. Volume 13, No. 3. P. 48-56. https://oi.org/10.47370/2078-1024-2021-13-3-48-56. 
Исследование проблем истории регионов России является актуальной задачей отечественной исторической науки. И в этой связи малоизученный опыт регулирования органами власти Кубанской области вопросов духовного управления мусульманскими сообществами в 80 -е гг. XIX в. имеет актуальное значение для понимания процесса становления российского гражданского управления, связанного с преодолением как предвзятого отношения российских чиновников к кавказским народам, так и боязнь, например адыгов (черкесов) потерять свою этническую идентичность и связь с мусульманским миром. Проявлялось такое негативное состояние черкесского населения Кубанской области в перманентном стремлении их переселиться на постоянное жительство в Турцию. Надо еще иметь в виду и то, что практически все волнения жителей черкесских аулов Кубанской области в 70-80-е гг. $\mathrm{XIX}$ в. имели религиозно-политический характер.

Научный интерес вызывают и подходы российских чиновников к регулированию деятельности мусульманских священнослужителей, что актуально для понимания выстраиваемого механизма вовлечения черкесских аульных обществ в политико-правовое пространство Российской империи.

Тема существования ислама в Российской империи нашла отражение, прежде всего, в исследованиях признанного отечественного историка В. Бобровникова, который указывает на то, что в последней четверти XIX в. перед Российской империей, взявшей к этому времени под свой контроль большое количество земель с мусульманским населением в Волго-Уральском регионе, Западной Сибири, Центральной Азии и на Северном Кавказе, встал «мусульманский вопрос»), дополняя уже и без того длинный список множества других «инородческих вопросов»: еврейский, балтийский, польский, украинский. «Отношения между царизмом и исламом, - как отмечает В. Бобровников, - следует понимать скорее как вовлечение во взаимодействие, чем противостояние. Признавая ислам с конца восемнадцатого века, органы власти выстроили сложную имперскую организацию исламских учреждений, включавших в себя мусульманское духовенство, приходы и четыре региональных муфтиата. Управление мусульманами различалось в Центральной России и на окраинах. В некоторых приграничных регионах, таких как Северный Кавказ и Центральная Азия, ислам не был институционализирован даже в конце режима» $[1$, с. 223]. Однако, по мнению автора, несмотря на длительную историю взаимодействия, кризис царизма, начавшийся в последней трети XIX в., порождал новые страхи и тревоги относительно ислама у царских чиновников.

В свою очередь, в исследованиях другого историка И.Л. Бабича отмечается, что в конце XIX в. - начале XX в. происходит активизация мусульманской жизни на национальных окраинах Российской империи. Кавказской администрации необходимо было создать механизм контроля над деятельностью мусульманского духовенства и оградить подданных мусульман от влияния Турции. Сложность процесса упорядочения жизни мусульман Северного Кавказа, по мнению ученого, заключалась в отсутствии самостоятельного духовного учреждения, которое объединяло мусульман региона. И несмотря на близость Закавказского магометанского управления, при возникновении спорных сложных ситуаций северокавказским мусульманам предлагалось обращаться за помощью в Оренбургское магометанское духовное собрание, которому они были подчинены. Хотя вопрос о реформировании управления мусульманским духовенством в Кубанской и Терской области ставился и в 80-е гг. XIX в., и в начале XX в., но по-прежнему 
ничего не менялось в жизни северокавказских мусульман. Также остро стоял вопрос об организации системы мусульманского образования [2, с. 76-77].

$\mathrm{He}$ менее интересные замечания мы находим в работах исследователя Н.А. Нефляшевой в отношении организации во второй половине XIX - начале $\mathrm{XX}$ вв. мусульманского образования и духовного управления на Северо-Западном Кавказе. По мнению Н.А. Нефляшевой, комплекс стереотипов русской политической элиты на всех уровнях власти предопределял отношение к северокавказским горцам как неуправляемым и «склонным к разбоям фанатикам-мусульманам» и связывал развитие религиозного фанатизма у горцев с созданием муфтиата и решением проблемы упорядочения духовной жизни. «Все проекты духовного управления для Северного Кавказа, - пишет автор, - а в самых поздних предусматривались возможности организации мусульманских школ с санкции региональных начальников, рассматривались как открывающие перспективы для возникновения нового центра консолидации мусульман и развития мусульманской антигосударственной активности в тех регионах Кавказа, где ислам не был широко распространен» [3, с. 77].

Тем не менее, до настоящего времени отечественной исторической наукой не раскрыт в полной мере исторический опыт регулирования органами власти Кубанской области в 80-е гг. XIX в. вопросов духовного управления мусульманскими сообществами. Мало исследованы подходы органов власти Кубанской области к повышению роли кадиев горских словесных судов в духовной жизни мусульманских сообществ, к конструированию механизма отбора и назначения аульных мулл, к выстраиванию территориальной организации мусульманских приходов в аульных кварталах (поселках). Не раскрыта роль гражданских уездных правлений и лично начальника Кубанской области в этом трудном процессе духовного регулирования, способствовавшему сохранению российского влияния и порядка в черкесских аульных обществах.

В ходе раскрытия проблемы автор следовал принципу научности и принципу объективности. В работе был использован соответствующий широкий круг источников по истории адыгов (черкесов), включавший и большой объем архивного материала, предполагающий всесторонний охват исторических фактов по данной проблеме. Значительную роль в изучении проблемы играет принцип историзма, позволивший рассмотреть деятельность органов гражданской власти Кубанской области в динамике от фактических событий в конкретных исторических условиях в тесной связи с этноконфессиональной политикой органов власти до рассуждений об их причинах и последствиях.

В 80-е гг. XIX в. российские чиновники всё чаще стали замечать распространение среди черкесского населения рассуждений о «противности исламу» службы мусульман в российских органах власти. Эти разговоры особенно обострялись, когда черкесское население подозревало видных уездных должностных лиц в корыстном интересе или желании нажиться за счет безграмотных мусульман. Так, Хачемзиевский аульный судья эфенди Индрис Берзегов распространял среди жителей аула вредные для российских властей идеи о том, что «служащие русскому правительству горцы в случае смерти недостойны погребения по мусульманскому обряду» [4, л. 3]. В итоге, по ходатайству начальника уезда эфенди Индрис Берзегов был уволен с должности аульного судьи за распространение таких провокационных мыслей. К тому же, Индрис Берзегов был обвинен в (пристрастных» действиях во время исполнения своих обязанностей аульного судьи и в сношениях с подозрительными людьми порочного поведения. Идея 
«об отлучении от общества мусульман» черкесов, служивших российскому правительству, использовалась людьми, недовольными властью, с целью дискредитации должностных лиц аульных правлений. Люди с сомнительной репутацией использовали и распространяли эти вредные для российской власти мысли и провоцировали беспорядки для получения большей свободы действий в аульных обществах и избавления от надзора, а заодно и для придания себе статуса поборников чистоты ислама и защитников интересов народа.

Начальник Кубанской области генерал-лейтенант Леонов, обеспокоенный независимым положением горского мусульманского духовенства, в августе 1884 г. представил на утверждение главноначальствующему гражданской частью на Кввказе генерал-адъютанту Дондукову-Корсакову проект изменений в действующем Положении об аульных обществах. «Нельзя не прийти к тому заключению, - писал начальник Кубанской области, - что при допущении выборов на должности аульных старшин и их помощников должности эти будут заняты в непродолжительном времени черкесскими книжниками муллами, и всю власть в аулах передадим в руки самой вредной части населения. Поступивши таким образом, мы лишены будем возможности знать о преступлениях, совершаемых горцами против русского населения, а если и узнаем от потерпевших или случайно, то настолько поздно, что невозможно будет обнаружить следы преступления, а на преследование этих преступлений со стороны аульных властей совсем нельзя будет рассчитывать» [5, л. 41]. По его мнению, необходимо было определить и строго ограничить круг обязанностей аульных мулл, в том числе и для того, чтобы таким образом прекратить натравливание муллами жителей на аульных старшин, не подверженных влиянию мулл, или лжесвидетельствование против старшин целыми аульными обществами.

Должность аульного муллы являлась выборной, и в силу своего духовного сана аульный мулла традиционно становился толкователем всех действий российских чиновников. Прежде всего, генерал-лейтенант Леонов посчитал необходимым не только ограничить влияние аульных мулл на работу должностных лиц аульного правления, но и вообще не допускать их к участию в общественных аульных сходах. Аульным муллам запрещалось занимать какие-либо общественные должности и даже присутствовать на аульных сходах, правда, только с одним исключением, если на аульном сходе не обсуждались вопросы, связанные с отправлением мусульманских религиозных обрядов или утверждением величины вознаграждений за проведение таких обрядов [5, л. 24-25 об.].

Вскоре российскими чиновниками были разработаны правила, по которым аульный мулла должен был вести свою деятельность в ауле. На должность аульного муллы обществом аула должны были избираться претенденты с положительной нравственной репутацией, имевшие свидетельство на право занимать должность аульного муллы, которое выдавалось уездным Горским словесным судом после прохождения экзаменационного испытания. Этот экзамен на основательное знание мусульманского вероучения принимала комиссия, состоящая из нескольких признанных авторитетов, образованнейших мусульманских священнослужителей уезда под председательством кадия Горского словесного суда. Однако к экзаменационному испытанию допускались только лица, получившие от начальника уезда свидетельство о нравственной благонадежности. Общее же количество мулл в каждом ауле предложено было определять упрощенно, отталкиваясь от количества жителей в ауле - по одному особому мулле на сто дворов. В который 
раз чиновники указывали на то, что аульный мулла обязан был заниматься лишь отправлением религиозных нужд населения. За любое вмешательство в дела, не входящие в круг его обязанностей, мог быть подвергнут строгому взысканию со стороны уездных чиновников вплоть до отстранения от должности и аннулирования выданного ему свидетельства о благонадежности [5, л. 28-29].

В свою очередь, обеспокоенный необходимостью усиления надзора за мусульманским духовенством в Кубанской области генерал-адъютант ДондуковКорсаков предложил использовать уже имеющийся опыт по организации деятельности мусульманского духовенства в Закавказье и распорядился созвать в 1886 г. особое совещание начальников уездов, народных кадиев и наиболее влиятельных лиц аульных обществ с целью составления записки о действительном положении мусульманского духовенства в области [6, л. 3-3 об.].

Надо отметить, что свою озабоченность удручающим положением дел в духовно-нравственном состоянии жителей аульных обществ ранее уже высказывал ряд народных кадиев Кубанской области. Так, в октябре 1880 г. народный кадий Майкопского горского словесного суда эфенди Хасан Шовгенов писал в своей докладной записке о том, что наблюдается новое явление, когда многие молодые черкесы, научившиеся писать и говорить на арабском языке, пытаются занять место аульного эфенди, и в немалой степени потому, что это давало хороший материальный доход. Для достижения своих целей молодые люди с помощью родственников и друзей стараются расколоть аульную мусульманскую общину на «партии» и, отделив какую-то часть сторонников, выбрать своего особого эфенди. Преследуя свои личные интересы, новоявленные муллы вмешиваются в общественные дела, провоцируя беспорядки и ссоры в аулах. «Пользуясь невмешательством власти в дела религиозные, - отмечал кадий Хасан Шовгенов, - нередко внушают населению противозаконные понятия о религиозном долге, будто бы не совмещающегося с требованиями закона, и вследствие таких ложных толкований поселяется в массе убеждение, что принятие ложной присяги в защиту своего единоверца против православного есть религиозный долг каждого магометанина» [7, л. 1-1 об.].

В другом заявлении, сделанном одним из уважаемых в Кубанской области мусульманских священнослужителей - кадием 1 Баталпашинского Горского словесного суда Умаром Мекеровым, также указывалось на необходимость установления порядка в деятельности мусульманского духовенства. «Духовно-нравственною частью наших горцев магометанского вероисповедания управляют эфенди, - писал уездный кадий Умар Мекеров, - которые над собою не имеют никакой контрольной власти из магометанского духовенства и признающими себя в кругу своего аула независимыми управителями ислама... Например, жители, самовольно приняв к себе эфенди, равно и эфенди самопроизвольно назначают себя к месту... Жители при самовольном приеме к себе эфенди часто ошибаются в выборе, принимая к себе не достойных и не сведующих, которые не в состоянии бывают решать много вопросов, касающихся требований магометанской религии, через что, также, происходят между эфенди и народом недоразумения и беспорядки» [6, л. 9-9 об., 1111 об.]. По его мнению, мусульманское духовенство в уездах области нуждалось в контрольной духовной власти или в лице одного муфтия на всю Кубанскую область, или в лице кадиев уездных Горских словесных судов. И без такой административно организующей меры нельзя было привести в порядок духовно-нравственную жизнь мусульман. 
Другим важным вопросом, вызывавшим споры в жизни аульной мусульманской общины по мнению кадия Екатеринодарского Горского словесного суда эфенди Ахмада Яхутля был вопрос о совершении молитвы в пятницу. Совершение молитвы в пятницу (время «джумы») должно было проходить для всех жителей аула в одной мечети. «Словом джума означается собрание населения, народа в одно место, для молитвы, - отмечал эфенди Ахмад Яхутль, - а между тем у нас в аулах общества никогда не собираются в одну мечеть для молитвы, а каждый квартал, имея своего эфенди (муллу), молится в своей мечети. Если бы это не противоречило Шариату, то об этом бы ничего не говорилось, между тем, как по мнению высоких имамов, несоблюдение джумы есть великий грех против религии... Кроме того, несоблюдение дня джумы приносит вред и для целого населения самого аула или поселка, между фамилиями... возникают целые ссоры» [6, л. 14-15 об.]. Решительно выступая за соблюдение в аулах общей молитвы жителей в одной мечети в пятницу, эфенди Ахмад Яхутль говорил о том, что прихожане, посещающие одну мечеть одного имама «отворачиваются) от тех, кто ходит в мечеть другого имама. Были случаи, когда при ссоре с имамом одной из мечетей прихожане уходили к другому имаму другой мечети, как бы показывая, что появление их в мечети есть способ выражения уважения к одному имаму и вражды к другому.

Кадий Екатеринодарского Горского словесного суда просил начальника Кубанской области о подготовке его распоряжения об обязательном строительстве в каждом аульном обществе одной большой мечети, которая смогла бы вместить всех прихожан этого общества и назначить в такую мечеть одного имама (старшего муллу) из эфенди наиболее ученых и безу коризненно честных, понимающих свои обязанности. Кроме того, он не исключал проведение выборов мусульманской общиной наиболее образованных эфенди в каждом ауле, избегая при этом родственных или враждебных отношений. В тех же аульных обществах, где ученых эфенди было мало, необходимо назначить самого лучшего из них [6, л. 15 об.].

Интересно, что накануне заседания особого совещания начальник Майкопского уезда ротмистр Соколов, признав предложения, сделанные кадием уездного Горского словесного суда эфендием Хасаном Шовгеновым, вполне справедливыми и подтверждавшимися многими фактами, предложил установить правила по организации выборов аульных эфендиев (мулл), обязательно включив в них такие положения:

- количество эфендиев в ауле определять исходя из числа жителей аула самим аульным обществам;

- аульных мулл избирать полными общественными сходами аула;

- всех претендентов на должность муллы подвергать испытанию народным кадием Горского суда на знание обязанностей аульного муллы;

- все религиозные споры между аульными эфендиями разрешать Горским судом с участием народного кадия [7, л. 3].

Заявление начальника Майкопского уезда о нарушении порядка в черкесских аулах из-за отсутствия правил в отношении назначения аульных мулл нашло живую поддержку у начальников Екатеринодарского и Баталпашинского уездов. Они подтвердили все высказанные ранее доводы о том, что «безграмотные» муллы в своих проповедях делают ложные толкования Корана, чтобы настроить жителей аулов против российской власти и установленного в аулах порядка. По мнению начальника Баталпашинского уезда, устранить это вредное явление можно было, только взяв под контроль сами выборы на должность аульного 
муллы и подняв уровень образования мулл [7, л. 8-9 об.].

В августе 1886 г. в Екатеринодаре было созвано особое совещание для составления записки о настоящем устройстве мусульманского духовенства в Кубанской области. Особое совещание проходило под председательством вицегубернатора Кубанской области, действительного статского советника Николича, с участием в заседание начальников уездов, кадиев горских словесных судов и почетных представителей аульных обществ [6, л. 30].

Прежде всего, особое совещание установило отсутствие какой-либо подчиненности и связи имамов аульных мечетей с народными кадиями уездных Горских словесных судов. Аульные имамы только тогда выполняют распоряжения уездного кадия, когда в этом они видят для себя какую-либо выгоду [6, л. 30-31 об.]. Однако народные кадии Горских словесных судов являлись высшими духовными лицами в уезде и разбирали поступавшие в суд дела по Шариату и по Китабу (толкованию Корана), поэтому им принадлежало главенство в мечети. К тому же, по издревле существовавшим правилам только кадий давал письменное удостоверение на арабском языке претендентам на звание муллы.

Сложившаяся порочная практика, когда кадии уездных Горских словесных судов не вмешивались в деятельность аульных мулл и не выдавали им разрешительных удостоверений, совершенно не устраивала заседателей особого совещания [6, л. 34-34 об.]. Особое совещание предложило начальнику Кубанской области усилить надзор за деятельностью мусульманского духовенства, особенно в вопросах исполнения ими религиозных обрядов и в соблюдении ими нравственных начал ислама.

Таким образом, до середины 80-х гг. XIX в. продолжала действовать вполне, как казалось, выгодная для российских властей доктрина, согласно которой отклонялись всякие попытки учреждения над адыгами (черкесами) организованных форм духовного управления, основанных на Шариате в виде институтов старших народных кадиев или муфтия. Ограничивая влияние мусульманского духовенства на аульные общества, российские чиновники уделяли больше внимания лояльности мусульманских священнослужителей российским властям. Однако, несмотря на то что были выработаны административные ограничения должностных функций аульных мулл, продолжал остро стоять вопрос об организации системы духовного управления мусульманами в Кубанской области и правильного варианта управления мусульманскими духовными лицами в Кубанской области как части общероссийского механизма упорядочения их деятельности. Находясь в состоянии крайней обеспокоенности, российские власти поставили вопрос об установлении лучшего надзора за мусульманским духовенством Кубанской области, используя уже имеющийся опыт по организации деятельности мусульманского духовенства в Закавказье, при этом стараясь не создавать перегруженный бюрократический аппарат. В лице кадиев уездных Горских словесных судов мусульманское духовенство получило контролирующую их духовную деятельность власть, и без такой административно-организующей меры нельзя было привести в порядок духовно-нравственную жизнь мусульман в уездах Кубанской области.

\section{ЛИТЕРАТУРА:}

1. Bobrovnikov V. Islam in the Russian Empire // The Cambridge History of Russia. Imperial Russia, 1689-1917. Edited by Dominic Lieven. Cambridge University Press. 2006. P. 202-223. 
2. Бабич И.Л. Мусульманская жизнь горцев в контексте религиозной политики России на Северном Кавказе в ХIX - начале ХХ вв. // Научная мысль Кавказа. 2009. № 1. С. 71-80.

3. Нефляшева Н.А. Мусульманское образование на Северо-Западном Кавказе (вторая половина ХІХ в. - начало ХХ в.) // Вестник МГУ. Серия, 13: Востоковедение. 2009. № 4. С. 72-92.

4. Государственный архив Краснодарского края (далее - ГАКК). Ф. 454. Оп. 7. Д. 1479.

5. ГАКК. Ф. 449. ОП. 2. Д. 13.

6. ГАКК. Ф. 454. ОП. 2. Д. 764.

7. ГАКК. Ф. 454. Оп. 7. Д. 1546.

\section{REFERENCES:}

1. Bobrovnikov V. Islam in the Russian Empire // The Cambridge History of Russia. Imperial Russia, 1689-1917. Edited by Dominic Lieven. Cambridge University Press. 2006. P. 202-223.

2. Babich I.L. Muslim life of the highlanders in the context of the religious policy of Russia in the North Caucasus in the 19th and early 20th centuries. // Scientific Thought of the Caucasus. 2009. No. 1. P. $71-80$.

3. Neflyasheva N.A. Muslim education in the Northwestern Caucasus (second half of the 19th - early 20th centuries) // Bulletin of Moscow State University. Series, 13: Oriental Studies. 2009. No. 4. P. $72-92$.

4. The State Archives of the Krasnodar Territory (hereinafter-SAKT). F. 454. Op. 7. D. 1479.

5. SAKT. F. 449. Op. 2. D. 13.

6. SAKT. F. 454. Op. 2. D. 764.

7. SAKT. F. 454. Op. 7. D. 1546. 